\title{
GLOBALIZAÇÃO SELETIVA E AUMENTO DA EXCLUSÃO SOCIAL NA SOCIEDADE EM REDE: REFLEXÕES A PARTIR DE MANUEL CASTELLS
}

\author{
Anabela Cristina Hirata ${ }^{1}$ \\ Zulmar Fachin ${ }^{2}$
}

\begin{abstract}
RESUMO
O tema do artigo é a sociedade em rede conceituada por Manuel Castells, com foco na análise da globalização seletiva da ciência e da tecnologia. Busca-se abordar a questão em torno da globalização e concentração de tecnologias em países de interesse científico geral, como fundamento para o aumento da exclusão na sociedade em rede. Adota-se o método dedutivo, utilizando-se de livros e artigos científicos. Conclui que a sociedade em rede integra uma estrutura que favoreceu grandes avanços tecnológicos, entretanto, embora as ciências e tecnologias sejam globais, as questões principais limitam-se às definições de países desenvolvidos. Trata-se de premissa para o aumento da exclusão social.
\end{abstract}

Palavras-chave: Desigualdade; Exclusão social; Globalização; Sociedade em rede; Tecnologia

\section{SELECTIVE GLOBALIZATION AND INCREASED SOCIAL EXCLUSION IN NETWORK SOCIETY: REFLECTIONS BASED ON MANUEL CASTELLS}

\begin{abstract}
The theme of the article is the network society conceptualized by Manuel Castells, focusing on the analysis of selective globalization of science and technology. It seeks to address the issue around globalization and concentration of technologies in countries of general scientific interest, as a basis for increasing exclusion in the network society. The deductive method is adopted, using scientific books and articles. It concludes that the network society integrates a structure that favored great technological advances, however, although sciences and technologies are global, the main issues are limited to the definitions of developed countries. It is a premise for increasing social exclusion.
\end{abstract}

Keywords: Inequality; Social exclusion; Globalization; Network society; Technology

\footnotetext{
1 Mestranda no Programa de Mestrado Profissional em "Direito, Sociedade e Tecnologias" da Escola de Direito das Faculdades Londrina. Bacharel em Direito pela Pontifícia Universidade Católica do Paraná. E-mail: anabelahirata@hotmail.com. ORCID - 0000-0002-8729-523X.

2 Doutor em Direito Constitucional (UFPR). Mestre em Direito (UEL). Mestre em Ciência Política (UEL). Bacharel em Direito (UEM). Licenciado em Letras (Unicesumar). Professor na UEL e no Programa de Doutorado e Mestrado em Ciência Jurídica na Universidade Cesumar - Unicesumar. Coordenador do Mestrado Profissional em "Direito, Sociedade e Tecnologias" da Escola de Direito das Faculdades Londrina. Membro eleito da Academia Paranaense de Letras Jurídicas. Presidente do IDCC - Instituto de Direito Constitucional e Cidadania. Pesquisador do Instituto Cesumar de Ciência, Tecnologia e Inovação. Bolsista Produtividade em Pesquisa do ICETI. E-mail: zulmarfachin@uol.com.br. ORCID - 0000-0001-5514-5547.
} 


\section{INTRODUÇÃO}

A sociedade em rede, conceituada por Manuel Castells, integra uma estrutura capaz de expandir-se de forma ilimitada, ou seja, é considera uma revolução capaz de modificar o padrão das bases materiais da economia, sociedade e cultura, impulsionando processos globalizantes e transformando a forma como vivemos. Trata-se de uma estrutura dinâmica que favoreceu grandes avanços tecnológicos e científicos nas duas últimas décadas do século XX. Ocorre que, apesar da característica independente da tecnologia e sua possibilidade de alcance ilimitado, verifica-se que os conectores dessa estrutura em rede garantem uma condução privilegiada dos instrumentos responsáveis por tais avanços.

Assim, o aumento da exclusão social e desigualdade na sociedade em rede é um paradoxo surpreendente, tendo em vista os inúmeros benefícios trazidos pela globalização. A questão, todavia, merece uma reanálise mais detida, pois é essencial compreender as razões que levam o fenômeno da globalização a ser tão seletivo e excludente em determinados territórios.

Os conectores da estrutura em rede, por integrarem uma relação de poder, adotam premissas que refletem em toda a estrutura social. Em outros termos, a concentração de riquezas e recursos em determinados territórios resulta em uma segmentação cada vez maior da população mundial.

As questões que oferecem pouco interesse científico geral, ou que se encontram fora de um mercado promissor, são desprezadas por programas de pesquisa dos países dominantes. A título exemplificativo, os medicamentos para tratamento da AIDS, por questões econômicas não têm alcance na África, muito embora a região apresente uma parcela significativa dos portadores do vírus.

Constata-se o paradoxo da globalização, porque de um lado apresenta vantagens e transformações positivas, especialmente no que diz respeito à tecnologia e comunicação, sendo fator decisivo para a melhoria nas relações entre os sistemas de economia internacional. De outro lado percebemos o aumento da exclusão e miséria. Surgem então diversas indagações a respeito da possibilidade de mudanças neste cenário, e se é possível, como reverter a contraditória realidade imposta pela globalização e suas novas formas de produção e consumo. 
Nesse contexto, o artigo tem como objetivo a análise da sociedade em rede descrita por Manuel Castells, especialmente no que diz respeito aos conceitos de produtividade e competitividade. Como consequência, busca-se analisar os reflexos que resultam em uma globalização seletiva da ciência e da tecnologia e o aumento da exclusão social, situação que será perceptível principalmente em países em desenvolvimento e com baixo interesse no mercado global.

\section{SOCIEDADE EM REDE E OS AVANÇOS TECNOLÓGICOS}

Em seu primeiro volume da trilogia "A era da informação: economia, sociedade e cultura", Manuel Castells (2020) descreve a sociedade atual diante das transformações em tecnologia, comunicação e seus impactos na ordem econômica e social. Em síntese, caracteriza a atual sociedade como sociedade em rede, visto que possui uma ligação entre diversos eixos, como economia, comunicação e até mesmo entre as relações sociais.

Compreende-se Rede como um conjunto de 'nós' interconectados. Para Castells, essas estruturas são ilimitadas, capazes de se expandir e integrar cada vez mais 'nós', desde que um possa se interconectar com o outro dentro desta rede de comunicação. Assim, conforme verificar-se-á no presente trabalho, é importante compreender que os conectores desses 'nós' são aqueles que detém o poder e que, portanto, a sociedade em rede é guiada por uma sociedade capitalista, já que dá forma às produções e relações sociais em todo o globo.

Neste contexto,

[...] a revolução da tecnologia da informação e a reestruturação do capitalismo introduziram uma nova forma de sociedade, a sociedade em rede. Essa sociedade é caracterizada pela globalização das atividades econômicas decisivas do ponto de vista estratégico; por sua forma de organização em redes; pela flexibilidade e instabilidade do emprego e a individualização da mão de obra. Por uma cultura de virtualidade real construída a partir de um sistema de mídia onipresente, interligado e altamente diversificado. E pela transformação das bases materiais da vida mediante a criação de fluxos e de um tempo intemporal como expressões das atividades e elites dominantes. (CASTELLS, 1999, p. 17).

Com base nessa premissa, inicia-se a abordagem deste tópico pela noção de produtividade e lucratividade caracterizadas por Castells como principais fatores de motivação do uso da tecnologia em empresas e nações (ou entidades políticas de diferentes níveis). Castells (2020) apresenta a ideia de que a produtividade é a fonte de riqueza das nações e que a tecnologia é o principal fator que induz à produtividade. Entretanto, ressalta que por uma perspectiva econômica a produtividade não é o objetivo em si. 
Em outros termos, as empresas e nações, agentes do crescimento econômico mundial, buscam a tecnologia com um objetivo e este não é o aumento da produtividade - e muito menos a melhoria dos aspectos da humanidade - ou seja, na mais pura realidade, buscam o lucro e o aumento do valor de suas ações (CASTELLS, 2020, p. 150).

Outro importante aspecto apresentado por Castells sobre a sociedade em rede é a ideia de competitividade do mercado financeiro global. Juntamente com a busca pela lucratividade, a economia informacional é moldada pelo interesse das instituições políticas em promover a competitividade entre as economias. Estudos constataram um melhor desempenho decorrente da busca pela lucratividade e consequente concorrência entre os próprios agentes econômicos, de forma a moldar a nova economia global que reflete até hoje no mercado.

Sobre os mercados financeiros globais, destaca-se que pela primeira vez o capital está em atividade durante 24 horas por dia, funcionando em tempo real e é globalmente integrado com outros mercados, o que justifica a sede por produtividade e competitividade. Assim, com relação à economia global, cumpre destacar que é uma economia com capacidade para funcionar em escala planetária:

Embora o modo capitalista de produção seja caracterizado por sua expansão contínua, sempre tentando superar limites temporais e espaciais, foi apenas no final do século XX que a economia mundial conseguiu tornar-se verdadeiramente global com base na nova infraestrutura, propiciada pelas tecnologias da informação e da comunicação [...]. (CASTELLS, 2020, p. 156).

As tecnologias da informação e comunicação proporcionaram a integração entre as nações ao redor do globo e o consequente aumento exponencial do processo de globalização. Por fim, a respeito da caracterizada sociedade em rede de Manuel Castells, vale registrar a preocupação do próprio autor acerca dos reflexos da nova era:

É o começo de uma nova existência e, sem dúvida, o início de uma nova era, a era da informação, marcada pela autonomia da cultura vis-à-vis as bases materiais de nossa existência. Mas este não é necessariamente um momento animador porque, finalmente sozinhos em nosso mundo de humanos, teremos de olhar-nos no espelho da realidade histórica. E talvez não gostemos da imagem refletida. (CASTELLS, 2020, p. 561).

Neste sentido, inicia-se a análise do fenômeno da globalização, para possibilitar a problemática a respeito do aumento da exclusão social como causa superveniente deste fator determinante. 


\section{GLOBALIZAÇÃO E SUAS CONSEQUÊNCIAS}

Já não subsiste qualquer dúvida de que a globalização é um processo irreversível e inevitável. Trata-se de processo histórico que aponta dimensões e conexões mundiais em diferentes esferas entre estados e sociedades, alcançando a economia, mercado de trabalho, cultura, meio ambiente, política, consumo e relações sociais. Para conceituar a globalização, Zygmunt Bauman menciona a percepção de "coisas fugindo ao controle", no sentido de considerar o fenômeno como um processo indeterminado, indisciplinado e de autopropulsão dos assuntos mundiais (BAUMAN, 1999, p. 65). Neste sentido, a globalização não é aquilo que se considera um empreendimento global, mas refere-se aos efeitos globais, algumas vezes não pretendidos e imprevistos.

As tentativas de definição conceitual serão tarefas difíceis, muito embora seja palavra frequentemente utilizada. Na definição de Kostas Vergopoulos, a globalização

[...] aparece hoje como a inevitável referência mítica em toda reflexão econômica, política e social contemporânea, como peça principal da nova ideologia dominante. A persistente desaceleração da atividade econômica nas duas últimas décadas, a aplicação de políticas restritivas e monetaristas, a extinção da coesão social com a instalação do desemprego em massa, da pobreza e das exclusões em larga escala, mesmo nos países industrializados, são apresentadas pela ideologia corrente como conseqüências diretas da globalização. (VERGOPOULOS, 2005, p. 43).

Em síntese, a perspectiva mais comum - seguida da perspectiva econômica - é a análise da globalização pelo viés social, isto porque se trata de fenômeno que acarretou uma consciência mundial sobre a abrangência de uma pluralidade de processos e estruturas sociais. A globalização, portanto, quase sempre envolverá um processo de mudanças, sejam políticas, geográficas, de estrutura social ou econômica. Neste sentido, qualquer tentativa de definição conceitual envolverá a análise das estruturas que compreendem a sociedade.

$\mathrm{Na}$ perspectiva de Manuel Castells o mundo está sendo moldado pelo processo transformador da globalização:

Essa nova forma de organização social, dentro de sua globalidade que penetra em todos os níveis da sociedade, está sendo difundida em todo mundo, do mesmo modo que o capitalismo industrial disseminado no século XX, abalando instituições, transformando culturas, criando riqueza e induzindo a pobreza, incitando a ganância a inovação e a esperança, e ao mesmo tempo impondo o rigor e instilando o desespero. Admirável ou não, trata-se na verdade de um mundo novo. (CASTELLS, 1999, p. 17). 
A globalização tomou proporção em diferentes escalas a partir dos anos 70 e 80 do século XX com a difusão das tecnologias de informação e comunicação, de tal forma que passou a integrar e redimensionar, além dos mercados financeiros globais, as relações econômicas entre nações, as atividades de trabalho, e até mesmo as relações sociais. Na lição de Ulrich Beck, a globalização reflete nas conexões entre estados e sociedades:

Globalidade significa o desmanche da unidade do Estado e da sociedade nacional,
novas relações de poder e de concorrência, novos conflitos e incompatibilidades
entre atores e unidades do Estado nacional por um lado e, pelo outro, atores,
identidades, espaços sociais e processos sociais transnacionais. (BECK, 1999, p. 49).

Vale ressaltar que os estudos da relação entre globalização, avanços tecnológicos, produtividade, crescimento econômico e desigualdade dependem da análise de fatores não só entre os países, mas também do interior desses, considerando que os processos de globalização são diferenciados. Os novos mecanismos de organização, distribuição de riquezas, produção e competitividade, geraram um impacto no desenvolvimento, que se mostrou mais intenso em países periféricos.

Na lição de Bauman:

A "globalização" está na ordem do dia; uma palavra da moda que se transforma
rapidamente em um lema, uma encantação mágica, uma senha capaz de abrir as
portas de todos os mistérios presentes e futuros. Para alguns, "globalização" é o que
devemos fazer se quisermos ser felizes; para outros, é a causa da nossa infelicidade.
Para todos, porém, "globalização" é o destino irremediável do mundo, um processo
irreversível; é também um processo que nos afeta a todos na mesma medida e da
mesma maneira. Estamos todos sendo "globalizados" - e isso significa basicamente
o mesmo para todos. (BAUMAN, 1999, p. 07)

É o paradoxo da globalização. Para alguns é o caminho que leva ao objetivo da felicidade, para outros, é a causa da infelicidade e miséria. Por ser um processo histórico de impacto mundial e social, a globalização alterou estruturas, principalmente no que diz respeito às formas de organização, trabalho e distribuição de renda. Em igual modo, a desigualdade também está presente em estrutura e é formada por diferentes grupos sociais, seja por exploração, hierarquia, exclusão ou segmentação.

Há quem entenda que a globalização é um produto do capitalismo, como uma fase superior que advém deste. Em síntese, o capital em seu processo de reprodução se expande tanto em profundidade - reordenando modos de vida e espaços já organizados e consolidados - como em extensão, através da incorporação de novos territórios. Tais movimentos 
dialeticamente conjugados conduzem, tendencialmente, à produção de um espaço global (HAESBAERT; LIMONAD, 2007, p. 41).

Segundo Ianni, pela globalização é possível caracterizar

um novo ciclo de expansão do capitalismo, como modo de produção e processo civilizatório de alcance mundial. Um processo de amplas proporções envolvendo nações e nacionalidades, regimes políticos e projetos nacionais, grupos e classes sociais, economias e sociedades, culturas e civilizações. (IANNI, 1996, p. 11).

Neste mesmo cenário, é oportuno citar Tania Steren dos Santos, ocasião em que diz que Marx já fazia referência às formas de expansão do capitalismo, ao mercado mundial e às transformações da grande indústria e dos monopólios, enfatizando o papel da burguesia no sentido de desenvolver o caráter internacionalista da produção e do consumo (SANTOS, 2001, p. 175).

Por outro lado, para Vergopoulos, a globalização não significa uma fase superior do capitalismo, "ao contrário, ela apenas maneja a recente degradação das condições de funcionamento da economia mundial, a exacerbação das disparidades de renda, a multiplicação das fraturas e exclusões em escala nacional e mundial" (VERGOPOULOS, 2005, p. 44).

A ideia de exclusão em escala nacional e mundial se adequa ao pensamento ilusório de que a globalização, por uma perspectiva sociocultural, é realmente formada pela homogeneização dos espaços globais. Esta não atinge igualmente a todos os espaços, sendo premissa de aumento da exclusão social. "A globalização tanto divide como une; divide enquanto une - e as causas da divisão são idênticas às que promovem a uniformidade do globo." (BAUMAN, 1999, p. 7).

\section{SELETIVIDADE E AUMENTO DA EXCLUSÃO SOCIAL}

O desenvolvimento da tecnologia e da comunicação implica em que a noção sobre os atores sociais da humanidade receba mais atenção e, por isso, a visão da desigualdade e este aumento da exclusão social torna-se cada vez mais evidente. Tal movimento está em processo e constante evolução desde o fim da Segunda Guerra Mundial e somente com o desenvolvimentismo pós-Segunda Guerra a desigualdade entre as nações do mundo recebeu atenção pública. A atual onda de globalização está provocando a comparação entre outras categorias humanas, como as mulheres do mundo, as crianças do mundo, e domicílios em todo planeta (THERBORN, 2001, p. 132). 
Para iniciar este tópico, há a seguinte questão a ser discutida: que tipos de processos geram a desigualdade global que estamos observando? Ressalta-se que "preocupar-se com a desigualdade, em vez de apenas com a pobreza, significa preocupar-se com a maneira como toda a sociedade é estruturada e não apenas com o seu pior aspecto" (THERBORN, 2001, p. 132).

A história global possui grande relevância sobre tais desigualdades. Por essa razão é que se faz necessário analisar quais foram os caminhos, ou pelo menos parte dos caminhos, para atingir a modernidade tal como é atualmente. Ainda sobre a perspectiva de Göran Therborn:

Não há dúvida de que este mundo é muito desigual. As conseqüências globais do
PIB per capita, da renda familiar, da renda por gênero, das expectativas de vida
nacional, por classe e por gênero, da educação nacional, por classe e por gênero e
assim por diante, são muito desiguais. No que diz respeito a um grande número de
recursos, ambientes e perspectivas, podem se elaborar classificações de vantagens e
desvantagens. (THERBORN, 2001, p. 136).

Para a análise de um dos processos que acarretam a desigualdade, é necessário retomar as características de produtividade e competitividade conceituadas por Castells e atribuídas à sociedade em rede e à globalização. A produtividade é elemento fundamental para a concorrência entre empresas e nações, para tanto, por existir grande interesse no crescimento econômico em escala global, utilizam-se da ciência e tecnologia como ferramentas para atrair e expandir a competitividade e o lucro. Neste sentido, a localidade e a forma como são distribuídos os investimentos em ciência e tecnologia são de fato situações que surtem efeito e interesse sobre as redes da economia global.

Conforme previamente exposto, verifica-se que os conectores da estrutura em rede ou seja, dos 'nós' que interligam os elementos da rede - são os estados, nações dominantes e empresas transnacionais com poder capital, que garantem uma condução privilegiada dos instrumentos responsáveis pelos avanços da globalização. Partindo desse pressuposto, fica clara a ideia de que muito embora sejam globais, diversos investimentos em ciências e tecnologias são direcionados para as questões estabelecidas por países avançados, pois geram mais interesse no mercado global, bem como nos três pontos discutidos anteriormente: produtividade, lucratividade e competitividade.

De fato, as pesquisas são difundidas pelas redes de interação mundial. No entanto, há uma tendência analisada por Castells que indica que os temas delimitados para a pesquisa 
científica tendem a ser definidos por países predominantes. Isso significa dizer que as questões essenciais para países em desenvolvimento, ou países periféricos, quando oferecem pouco interesse científico geral, ou quando não têm um mercado global interessado, são negligenciados pelos programas de pesquisa dos países desenvolvidos (CASTELLS, 2020, p. 178).

Os exemplos trazidos por Castells apontam situações inimagináveis e lamentáveis pelo ponto de vista social:

[...] uma vacina eficaz contra a malária poderia salvar a vida de dezenas de milhões de pessoas, principalmente crianças, mas dedicam-se poucos recursos a um empenho persistente para a sua descoberta, ou para divulgar no mundo inteiro os resultados dos tratamentos promissores, em geral patrocinados pela Organização Mundial da Saúde. Os medicamentos para tratamento da aids criados no Ocidente são caros demais para uso na África, ao passo que cerca de 95\% dos portadores do vírus HIV estão no mundo em desenvolvimento (CASTELLS, 2020, p. 178).

A respeito dos medicamentos, insta salientar outro fator gerado pela sociedade em rede. As empresas farmacêuticas multinacionais são as mesmas empresas que visam ao lucro do capital, o que significa dizer que não se dedicam à produção de medicações mais baratas, porque isso acarretaria em perda dos elementos que fazem a roda da economia lucrativa girar. Vale registrar a ideia principal, objeto do presente trabalho:

[...] as ciências são globais, mas também reproduzem em sua dinâmica interna o processo de exclusão de um número significativo de pessoas, pois não trata de seus problemas específicos, ou não os trata de maneira que possa produzir resultados que levem à melhoria de suas condições de vida. (CASTELLS, 2020, p. 178).

Sobre as mudanças e movimentos da globalização, o entendimento de Bauman:

Todos nós estamos, a contragosto, por desígnio ou à revelia, em movimento. Estamos em movimento mesmo que fisicamente estejamos imóveis: a imobilidade não é uma opção realista num mundo em permanente mudança. E no entanto os efeitos dessa nova condição são radicalmente desiguais. Alguns de nós tornam-se plena e verdadeiramente "globais"; alguns se fixam na sua "localidade" — transe que não é nem agradável nem suportável num mundo em que os "globais" dão o tom e fazem as regras do jogo da vida. (BAUMAN, 1999, p.15).

Já sobre a ideia de exclusão social, não se pode considerar que diz respeito tão somente à seletividade da pesquisa em ciência e tecnologia. Conforme o entendimento apresentado por Gerry Rodgers, é possível caracterizar três tipos de exclusão social, sendo que em sua essência a exclusão é multidimensional, incluindo não só a falta de acesso a bens e serviços, mas também à segurança, à justiça e à cidadania, ou seja, relaciona-se às 
desigualdades econômicas, políticas, culturais e étnicas. Pode-se considerar ainda a exclusão do mercado de trabalho, do trabalho regular, do acesso às moradias decentes e a serviços comunitários (RODGERS, 1997, p. 44).

A partir deste significado apontado para exclusão social, é possível tomar como referência a cidade do capitalismo fordista-industrial no que diz respeito à segregação urbana utilizada como mecanismo na formação de classes sociais, situações em que os bairros operários - excluídos - expressavam a divisão social da sociedade, ainda que posteriormente tenham sido utilizados como mecanismos de resistência. Assim, tem-se que a segregação socioespacial, isto é, a estrutura urbana também é um fator que interfere no exercício efetivo do direito de cidadania, o que resulta em mecanismo de reprodução da desigualdade social (RIBEIRO; SANTOS JUNIOR, 2005, p. 93).

A concentração de recursos, direcionamento seletivo das novas tecnologias e segregação socioespacial, resultará na segmentação cada vez maior da população mundial, a qual, acompanhada da segmentação da economia, levará ao aumento da desigualdade e exclusão. Em outras palavras, Gilberto Dupas (1999) ilustra que o capitalismo atual convive com duas dialéticas centrais: concentração versus fragmentação e exclusão versus inclusão.

A atual economia global é dinâmica, seletiva, exclusionária e instável. François Chesnais (1996) notabiliza o caráter desta nova economia, caracterizando-a como a economia que é guiada tão somente pelo movimento do capital. Neste sentido, de forma clara verificamse as características supramencionadas, isto porque há muito se sabe que é próprio do capitalismo dividir, marginalizar e excluir (LIMOEIRO-CARDOSO, 1999, p. 110).

$\mathrm{O}$ atual cenário ocasionado pelo novo coronavírus (Sars-CoV-2) demonstra as teses apresentadas: países que não investem em ciência e tecnologia, dependem da tecnologia de outros países quanto a insumos e vacinas contra o vírus e não têm políticas públicas, acarretam a seletividade que acaba por atingir as camadas mais pobres da população. Ainda, as condições socioespaciais do país são um terreno fértil para ampliar as desigualdades e vulnerabilidades da população. Apesar de ser um vírus globalizado, este não acarreta iguais consequências por todos os territórios e grupos sociais. Em relação aos territórios e uma análise comparativa com outros agentes atingidos pela pandemia, dados apresentados pela 
Our World in Data $^{3}$ mostram que até a data de 30 de março de 2021 apenas 6,64\% da população brasileira recebeu pelo menos uma dose da vacina contra o Covid-19, ao passo em os números na Alemanha estão em 11,25\%, nos Estados Unidos em 28,72\%, na Inglaterra em $45,19 \%$ e como último exemplo, em Israel a porcentagem sobe de forma disparada para $60,50 \%$ da população.

Os impactos do Covid-19 possuem repercussões econômicas assimétricas entre os países. Senhoras (2020) aduz que os "efeitos de transmissão ressoam no espaço e no tempo de modo distinto conforme o grau de sensibilidade e vulnerabilidade macroeconômica dos países e microeconômica das cadeias globais de produção e consumo" (SENHORAS, 2020, p. 2). O autor ainda afirma que, quanto mais tempo for necessário para conter a difusão do vírus, maiores serão os impactos não apenas em relação aos seres humanos, mas também em relação às economias mundiais, que seguem em desaceleração dia após dia. Neste sentido, as iniciativas transnacionais de cooperação científica e tecnológica são essenciais e urgentes para conter a difusão em termos humanos e econômicos (SENHORAS, 2020, p. 5).

Diante deste cenário, a desaceleração econômica acarretará em graves consequências para o mercado global, com falência de pequenas e médias empresas, restrição ao comércio exterior, queda do mercado de capitais e aumento do desemprego (SENHORAS, 2020, p. 5). Em relação aos grupos sociais, a pandemia atingirá as camadas da população que se encontram em maior vulnerabilidade socioeconômica. Segundo Barbosa (2020), os sujeitos em situação de desproteção às exposições ao contágio são os trabalhadores cujas condições sociais e urbanas acarretam por si só em vulnerabilidade, visto que as relações de trabalho em precarização de vínculos formais e o desemprego os levam à necessidade de manutenção do trabalho. São entregadores de mercadorias, vendedores em supermercados, motoristas de ônibus, vendedores em trens, ambulantes no comércio de rua, entre outras situações que impedem a quarentena (BARBOSA, 2020, p. 3). Este é o abismo da desigualdade, em termos sociais, econômicos e agora em relação ao Covid-19.

No Brasil, as relações trabalhistas formais estão sendo substituídas pela informalidade do mercado de trabalho. Como trabalhadores informais, considera-se o conjunto de trabalhadores sem carteira de trabalho, empregadores sem registro, trabalhadores autônomos e

\footnotetext{
3 Os dados apresentados pela Our World in Data dizem respeito à parte da população total que recebeu pelo menos uma dose da vacina contra Covid-19. Os dados podem não ser iguais à parcela que está totalmente vacinada se a vacina exigir duas doses.
} 
trabalhadores familiar auxiliar (Loschi, 2020). Registra-se que em 2019 a taxa média nacional de informalidade da população ocupada atingiu seu maior nível desde 2016 no Brasil, chegando ao marco de 41,1\% (IBGE, 2019). Em outros termos, os grupos de trabalhadores informais, diante da precarização das relações trabalhistas, sem amparo e defesa institucional nos períodos de crise econômica, serão diretamente atingidos pela limitação de políticas públicas em saúde e políticas de distribuição de renda básica.

Ainda para Barbosa, os trabalhadores identificados como vulneráveis à epidemia global "residem, em sua expressiva maioria, em favelas e periferias de nossas metrópoles, cujas condições urbanas de saneamento e de equipamentos de saúde pública estão longe de adequadas às demandas regulares" (BARBOSA, 2020, p. 3). A condição socioeconômica atua diretamente na minimização ou na expansão do vírus pelo território brasileiro, Pablo Ibañes, professor do departamento de geografia da Universidade Federal Rural do Rio de Janeiro, explicita que se as metrópoles, que comportam indivíduos de grande visibilidade social e impacto na economia, ainda assim são os maiores focos da doença no Brasil, quando a doença migra para o interior, se torna mais invisível socialmente à medida que se torna mais letal (RODRIGUES; LANDIM; SANTOS, 2020, p. 05).

Pesquisas sobre o avanço da Covid-19 e diagnóstico geográfico sobre a Baixada Fluminense $^{4}$, apontam que o avanço do vírus na região periférica revela as inúmeras fragilidades características desta realidade urbana. Rocha (2020) ressalta que o problema está além do adensamento populacional, pois possuem uma política de saúde aquém da demanda, o mercado de trabalho informal e subemprego crescente, além do sistema sanitário precário, fatores que potencializam a disseminação do vírus (ROCHA, 2020, p. 8).

A despeito da demanda pela produtividade e lucratividade no mundo globalizado, tal condição implica em um modelo de privatização da gestão da saúde em níveis mundiais. Rocha (2020) enfatiza a forma como Estado gere políticas públicas de saúde como parte de uma agenda neoliberal, e que neste ponto, o setor privado não detém de estrutura para atender

\footnotetext{
4 "Em nossos estudos concebemos a Baixada Fluminense como uma região formada pelos munícipios de Guapimirim, Magé, Duque de Caxias, Nova Iguaçu, Belford Roxo, São João de Meriti, Nilópolis, Mesquita, Belford Roxo, Queimados, Japeri, Paracambi, Seropédica e Itaguaí. Popularmente conhecida por uma representação hegemônica que a associa à pobreza, à violência e ao descaso social, estamos diante de uma periferia fortemente conturbada com a cidade do Rio de Janeiro marcada por intenso adensamento populacional e problemas sociais e de infraestrutura graves.”. ROCHA, André Santos da. Globalização, gestão e acesso aos sistemas público e privado de saúde: a Baixada Fluminense no contexto da pandemia. Espaço e Economia, n. 18, 2020, p. 8. Disponível em: <http://journals.openedition.org/espacoeconomia/12672>. Acesso em 03 Abr. 2021.
} 
as necessidades básicas em tempos de colapso, o que reproduz o ciclo de desigualdades direcionadas aos territórios periféricos (ROCHA, 2020, p. 3).

É importante destacar que os impactos da globalização e direcionamento da ciência e tecnologia, podem resultar em riscos à saúde global por uma perspectiva além da pandemia ocasionada pelo novo coronavírus. Em razão das mudanças sociais, culturais e econômicas advindas do processo de globalização, verifica-se a perpetuidade e exacerbação das diferenças econômicas inter e intra países, a fragmentação e enfraquecimento dos mercados de trabalho o que resulta em uma maior aceitação pelos trabalhadores para atuarem sob condições sanitárias e de segurança insalubres - e a degradação do meio ambiente, com a diminuição da biodiversidade e dispersão de poluentes (FORTES; RIBEIRO, 2014, p. 367).

Globalização e seletividade podem ser vistas como uma encruzilhada. Não obstante os avanços tecnológicos, há o aumento da concentração de renda e exclusão social, guiada por países de capitalismo central em face de países de capitalismo periférico. Além da própria estrutura de segregação interna de uma sociedade, que por si só acarreta um mecanismo de reprodução das desigualdades econômicas e sociais. David Harvey (1980) em sua pesquisa sobre justiça social e cidade, já aduziu que esta dinâmica socioespacial reflete tanto na estrutura de segregação urbana da sociedade, quanto provoca o mecanismo de aumento e reprodução de desigualdades em face das oportunidades de participação e distribuição de riquezas geradas na sociedade.

\section{CONCLUSÃO}

O estudo buscou situar a sociedade em rede e o advento do acelerado desenvolvimento da globalização enquanto fator de mudança social, política e econômica. O novo padrão, como se tentou mostrar, fundamenta-se pelo interesse daqueles que detém o poder de guiar os "nós" da sociedade em rede. Em outros termos, há a classe detentora do modo de produção e da forma como as pesquisas em ciência e tecnologia serão direcionadas. Há, de um lado, uma classe guiada pela competitividade e pela produtividade e, de outro, a classe segregada pelo desenvolvimento.

A globalização, incluída neste cenário, pode ser classificada como fenômeno do capitalismo. Ao mesmo tempo em que apresenta a ascensão de certas estruturas, como para o setor econômico internacional, apresenta também o aumento da disparidade de renda, ou seja, influencia o ciclo de exclusão social, desigualdade e miséria. 
A partir desta ideia, inicia-se a abordagem acerca da seletividade da pesquisa em ciência e tecnologia. Conforme tópicos anteriores, a seletividade é visível em países cujos interesses se mostram mais agradáveis e rentáveis ao mercado financeiro global, fator este que contribui com o aumento da desigualdade social porque limita o desenvolvimento principalmente dos países periféricos. $\mathrm{O}$ direcionamento dos investimentos em pesquisa aos países desenvolvidos e a desatenção com os demais ambientes que necessitam deste apoio são o resumo do que se entende por globalização seletiva.

Em síntese, entende-se que os novos métodos de produção, desenvolvimento e tecnologia devem ser socializados de forma direta e consciente, seguindo aquilo que são necessidades dos indivíduos de uma forma geral e não tão somente aqueles com mais rentabilidade e interesse econômico mundial. A característica de seletividade da mundialização é o resultado de um modelo socioeconômico cujos resultados positivos e negativos devem ser reavaliados a fim de identificar os fatores para uma possível mudança social.

Em conclusão, esta pesquisa aponta que as ciências e tecnologias, em tese globais, reproduzem o processo de exclusão de um número significativo de pessoas. Tem havido uma concentração de recursos e esforços apenas em países cuja economia garante um mercado promissor, de forma a não tratar de problemas específicos com resultados que levem à melhoria das condições de vida nos países em desenvolvimento. A pesquisa não comporta todas as respostas para os questionamentos necessários, pelo que se verifica a evidente necessidade de uma ampla discussão sobre o tema proposto, considerando as perspectivas social, econômica, política e geográfica.

\section{REFERÊNCIAS}

BARBOSA, Jorge Luiz. Por uma quarentena de direitos para as favelas e as periferias! Espaço e Economia, n. 17, 2020. Disponível em: <http://journals.openedition.org/espacoeconomia/10274; DOI: https://doi.org/10.4000/espacoeconomia.10274>. Acesso em: 03 Abr. 2021.

BAUMAN, Zygmund. Globalização: as consequências humanas. Rio de Janeiro: Jorge Zahar, 1999.

BECK, Ulrich. O que é globalização? Equívocos do globalismo: respostas à globalização. Tradução de André Carone. São Paulo: Paz e Terra, 1999. 
CASTELLS, Manuel. A sociedade em rede. São Paulo: Paz e Terra, 2020. v.1. O poder da identidade, São Paulo: Paz e Terra, 1999.

CHESNAIS, François. A mundialização do capital. São Paulo: Xamã, 1996

DUPAS, Gilberto. Globalização, exclusão social e governabilidade. In: I Conferência Latino - Americana e Caribenha de Ciências Sociais, Recife, 25 de novembro de 1999.

FORTES, Paulo Antônio de Carvalho; RIBEIRO, Helena. Saúde Global em tempos de globalização. Saúde soc., São Paulo, v. 23, n. 2, p. 366-375, Jun 2014. Disponível em: $<$ http://www.scielo.br/scielo.php?script=sci_arttext\&pid=S010412902014000200366\&lng=en\&nrm=iso>. Acesso em: 01 Abr. 2021. https://doi.org/10.1590/S0104-12902014000200002.

HAESBAERT, Rogério; LIMONAD, Ester. O território em tempos de globalização. In: etc., espaço, tempo e crítica. Revista Eletrônica de Ciências Sociais Aplicadas e outras coisas. Rio de Janeiro, n. 2(4), v. 1, 2007. Disponível em:

<https://www.researchgate.net/publication/228455262_O_territorio_em_tempos_de_globaliza cao>. Acesso em: 13 Fev. 2021.

HARVEY, David. A justiça social e a cidade. São Paulo: Hucitec, 1980.

IANNI, Octavio. Teorias da globalização. Rio de Janeiro: Civilização Brasileira, 1995.

LIMOEIRO-CARDOSO, Miriam. Ideologia da globalização e (des)caminhos da ciência social. In: GENTILI, Pablo (org). Globalização excludente. Desigualdade, exclusão e democracia na nova ordem mundial. Petrópolis: Editora Vozes, 1999.

LOSCHI, Marília. Desemprego cai em 16 estados em 2019, mas 20 têm informalidade recorde. Agência IBGE Notícias. Disponível em:

$<$ https://agenciadenoticias.ibge.gov.br/agencia-noticias/2012-agencia-denoticias/noticias/26913-desemprego-cai-em-16-estados-em-2019-mas-20-tem-informalidaderecorde>. Acesso em: 03 Abr. 2021.

RIBEIRO, Luiz César de Queiroz. SANTOS JUNIOR, Orlando Alves dos. Democracia e cidade: divisão social da cidade e cidadania na sociedade brasileira. Análise Social, Lisboa, n. 174, p. 87-109, abr. 2005. Disponível em:

$<$ http://www.scielo.mec.pt/scielo.php?script=sci_arttext\&pid=S0003-

25732005000200004\&lng=pt\&nrm=iso>. Acesso em: 10 Fev. 2021.

RITCHIE, Hannah; ORTIZ-OSPINA, Esteban; BELTEKIAN, Diana; MATHIEU, Edouard; HASELL, Joe; MACDONALD, Bobbie; GIATTINO, Charlie; APPEL, Cameron; ROSER, Max. Coronavirus (COVID-19) Vaccinations. Our World In Data, 2021. Disponível em: < https://ourworldindata.org/covid-vaccinations>. Acesso em: 30 Mar. 2021. 
ROCHA, André Santos da. Globalização, gestão e acesso aos sistemas público e privado de saúde: a Baixada Fluminense no contexto da pandemia. Espaço e Economia, n. 18, 2020. Disponível em: <http://journals.openedition.org/espacoeconomia/12672>. Acesso em: 03 Abr. 2021.

RODGERS, Gerry. What is special about a social exclusion approach? In: Garry Rogers, Charles Gore \& Figueiredo, José (orgs.). Social exclusion: rethoric, reality, responses. USA, International Institute for Labor Studies, 1995. Disponível em: <https://www.researchgate.net/publication/44819240_Social_Exclusion_Rhetoric_Reality_Re sponses>. Acesso em: 10 Fev. 2021.

RODRIGUES, André Luiz Teodoro; LANDIM, Gabriel de Paula Barbosa; SANTOS, Jonathan Christian Dias dos. Dossiê Coronavírus: A pandemia da globalização ou globalização da pandemia? Impactos espaciais da crise sanitária no sistema capitalista. Espaço e Economia [Online]: 2020. Disponível em: <http://journals.openedition.org/espacoeconomia/18217>. Acesso em: 30 Mar. 2021.

SANTOS, Tânia Steren dos. Globalização e exclusão: a dialética da mundialização do capital. Sociologias, Porto Alegre, n. 6. p. 170-198, Dez. 2001. Disponível em: < http://www.scielo.br/scielo.php?script=sci_arttext\&pid=S151745222001000200008\&lng=en\&nrm=iso>. Acesso em: 05 Fev. 2021.

SENHORAS, Eloi Martins. Novo coronavírus e seus impactos econômicos no mundo. Boletim de Conjuntura (BOCA), Boa Vista, v. 1, n. 2, p. 39-42, fev. 2020. Disponível em: <https://revista.ufrr.br/boca/article/view/Coronavirus〉. Acesso em: 03 Abr. 2021.

THERBORN, Göran. Globalização e desigualdade: questões de conceituação e esclarecimento. Sociologias, Porto Alegre, n. 6, p. 122-169, Dez. 2001. Disponível em: $<$ http://www.scielo.br/scielo.php?script=sci_arttext\&pid=S151745222001000200007\&lng=en\&nrm=iso>. Acesso em: 05 Fev. 2021.

VERGOPOULOS, Kostas. Globalização: o fim de um ciclo. Rio de Janeiro: Contraponto, 2005 . 